\title{
过渡金属催化法合成平面手性二茂铁衍生物的新进展
}

\author{
王艳芳 $^{a}$ 张安安 ${ }^{b, c}$ 刘澜涛 ${ }^{*}, b$ 康建勋 ${ }^{c}$ 张富强 ${ }^{a}$ 马文瑾 $*, a$ \\ ( ${ }^{a}$ 山西师范大学化学与材料科学学院 临汾 041004) \\ $\left(^{b}\right.$ 商丘师范学院化学化工学院 商丘 476000) \\ ( ${ }^{c}$ 郑州大学化学与分子工程学院 郑州 450052)
}

\begin{abstract}
摘要 平面手性二茂铁衍生物已经发展成为不对称催化反应中一类良好的手性配体和手性催化剂. 高效、高对映选择 性的平面手性二茂铁衍生物合成方法研究是不对称催化研究的热点之一. 综述了近年来利用过渡金属催化法合成面手 性二茂铁衍生物的进展.

关键词 过渡金属催化; 合成; 面手性二茂铁衍生物; 不对称 C- $\mathrm{H}$ 活化
\end{abstract}

\section{Recent Advances in Transition-Metal-Catalyzed Enantioselective Syntheses of Planar Chiral Ferrocenes}

\author{
Wang, Yanfang ${ }^{a} \quad$ Zhang, An'an ${ }^{b, c}$ \\ Liu, Lantao*,b \\ Kang, Jianxun ${ }^{c} \quad$ Zhang, Fuqiang ${ }^{a}$ \\ Ma, Wenjin*,a \\ ( ${ }^{a}$ School of Chemistry and Material Science, Shanxi Normal University, Linfen 041004) \\ ( ${ }^{b}$ College of Chemistry and Chemical Engineering, Shangqiu Normal University, Shangqiu 476000) \\ ( ${ }^{c}$ College of Chemistry and Molecular Engineering, Zhengzhou University, Zhengzhou 450052)
}

\begin{abstract}
Planar chiral ferrocene derivatives have been proved to be effective ligands and catalysts in asymmetric catalysis. The study toward enantioselective synthesis of planar chiral ferrocenes became one of the high hot spots. In this paper, the recent advance in transition-metal-catalyzed menthods for the syntheses of planar chiral ferrocenes is reviewed.
\end{abstract}

Keywords transition-metal-catalyzed; synthesis; planar chiral ferrocenes; asymmetric C- $\mathrm{H}$ activation

自从 20 世纪 50 年代二茂铁被成功合成以来, 化学 家们对二茂铁及其衍生物的合成、性能及应用研究等方 面进行了深入而广泛的研究. 相关研究成果也极大地推 动了合成化学、金属化学、材料科学等相关学科的发展, 二茂铁衍生物已广泛应用于生物、医学、染料、分子识 别、不对称合成及催化等诸多领域 ${ }^{[1 \sim 4]}$. 因其特殊的立 体结构、电子效应和稳定性等优点, 面手性二茂铁衍生 物已经发展为不对称催化反应中的一类优良的手性配 体和手性催化剂, 一些平面手性二茂铁配体应用于生物 素、手性农药的工业生产 ${ }^{[5]}$. 因此, 简捷、经济、高收率、 高选择性的合成平面手性二茂铁衍生物合成方法研究, 具有重要的理论意义与实用价值, 也是不对称催化的一 个热点研究领域.
平面手性二茂铁衍生物的经典合成方法主要有: (1) 中心手性二茂铁衍生物诱导的非对映选择性邻位锂化; (2)外加等物质的量的手性配体辅助的单取代二茂铁衍 生物的对映选择性邻位锂化; (3)媒介拆分; (4)由手性环 戊二烯衍生物合成平面手性二茂铁衍生物等. 上述经典 方法虽在面手性二茂铁衍生物的合成中取得了很大的 成功，但是他们也存在原子经济性不高、等物质的量的 手性试剂的消耗、官能团容忍性不好等缺陷. 过渡金属 催化剂发展尤其是最近兴起的过渡金属催化的不对称 C-H 活化的发展为面手性二茂铁衍生物的合成提供了 新的契机. 本文主要对近年来过渡金属催化法合成平面 手性二茂铁衍生物的新进展作简单介绍.

*E-mail: liult05@iccas.ac.cn; ma_w_j@163.com

Received February 23, 2015; revised March 24, 2015; published online March 25, 2015.

Project supported by the National Natural Science Foundation of China (No. 21202095), the Program for Science \& Technology Innovation Talents in Universities of Henan Province (No. 14HASTIT016) and the Natural Science Foundation of Shanxi Province (No. 2012011009-4).

国家自然科学基金(No. 21202095)、河南省高校科技创新人才基金(No. 14HASTIT016)和山西省自然科学基金(No. 2012011009-4)资助项目. 


\section{1 金属铜催化的反应}

1997 年 Siegel 课题组 ${ }^{[6]}$ 利用手性双啞唑啉配体和 $\mathrm{CuOTf}$ 组成的络合物为催化剂, 在温和的条件下实现了 铜卡宾对茂环 $\mathrm{C}-\mathrm{H}$ 键的对映选择性插入反应，合成了 环状面手性二茂铁衍生物(Eq. 1.), ee 值可以达到 $78 \%$ 。 该反应将已知的卡宾化学修饰苯环衍生物方法应用到 茂环的修饰, 为不对称催化合成面手性二茂铁衍生物提 供了一种独特的思路, 但是反应底物的局限性极大地限 制了该方法的发展和在不对称合成中的进一步应用.

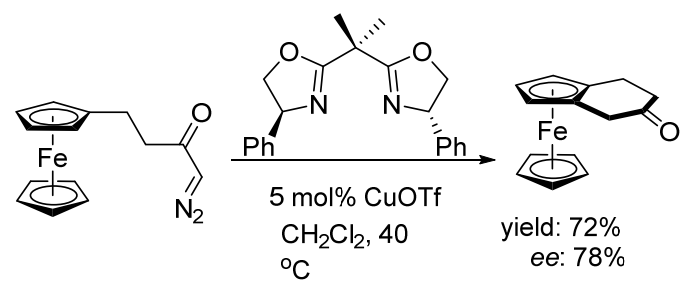

\section{2 金属铑催化的反应}

2007 年 Shintani 和 Hayashi 课题组 ${ }^{[7]}$ 利用 Rh 和手性 双烯配体为催化剂实现了芳基硼酸对二茂铁苯醌的不 对称共轭加成(Eq. 2), 合成了同时具有中心手性 $(R)$ 和平 面手性 $\left(R_{\mathrm{P}}\right)$ 的二茂铁衍生物, 并且取得了非常理想的结 果.

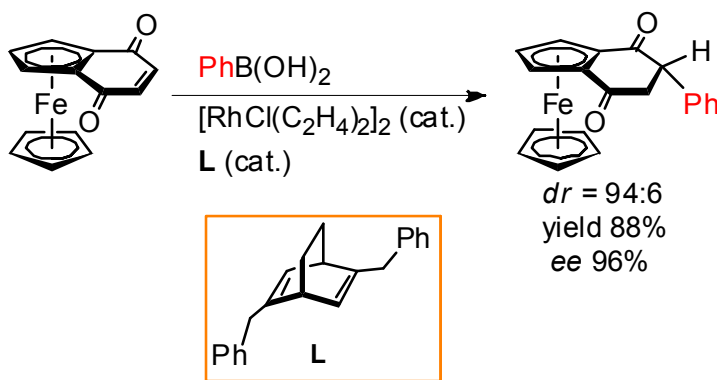

\section{3 金属钼催化的反应}

2010 年, Ogasawara 课题组 ${ }^{[8]}$ 以联菱酚修饰的手性 Mo 卡宾的络合物为催化剂, 利用烯烃的不对称复分解 关环反应成功合成了平面手性膦杂二茂铁衍生物(Eq. $3)$, 并取得了高达 $99 \%$ ee 值. 本反应的不足之处是: 所 用催化剂昂贵, 制备困难, 并且反应底物的取代基的变 化对催化剂的取代基变化依赖性较强.

\section{4 金属铱催化的反应}

2012 年, Shibata 课题组 ${ }^{[9]}$ 报道了 $\left[\operatorname{Ir}(\operatorname{cod})_{2}\right]$ BARF 催 化的吡啶导向的二茂铁邻位 $\mathrm{C}-\mathrm{H}$ 键直接烯基化和烷基 化反应(Eqs. 4，5), 合成了消旋的二取代二茂铁衍生物
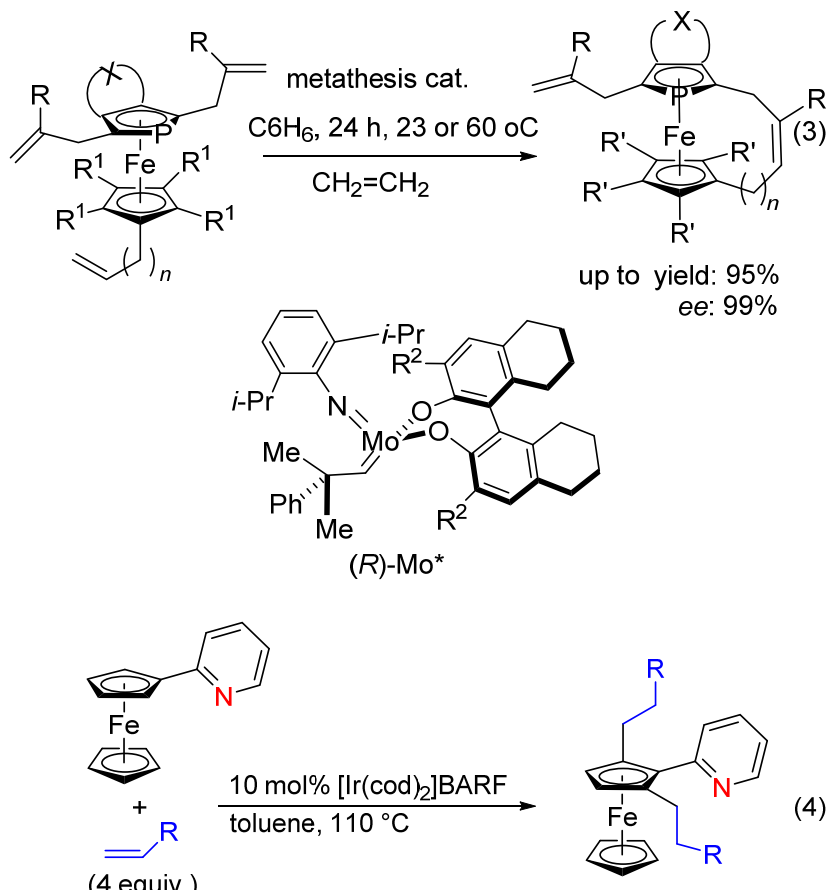

up to yield $99 \%$
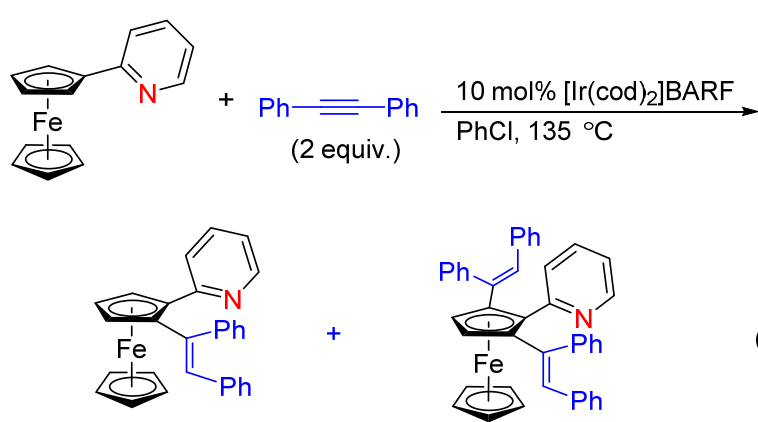

或三取代的二茂铁衍生物. 同时该课题组还对二茂铁上 连有不同定位基团的底物进行了考察(图 1), 当以 $N$-苯 基甲基二茂铁基亚胺为底物时，可以以较高的产率得到 相应的三取代的烷基化二茂铁衍生物; 当以异喹啉基作 为导向基团时，在所选的条件下能以 $77 \%$ 的产率得到外 消旋的二取代的烯基化二茂铁衍生物; 同样当导向基团 换成二苯基膦氧基时，相应的二取代的烯基化二茂铁基 膦氧衍生物也可以较低产率得到. 在此基础上，该课题 组 ${ }^{[10]}$ 在 2014 年以 $\mathrm{Ir}$ 和手性双烯配体组成的络合物为催

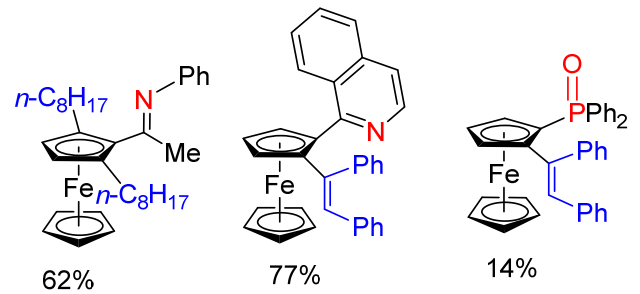

图 1 不同的导向基的影响

Figure 1 The influence of different directing groups 
化剂实现了二茂铁基异喹啉的对映选择性 $\mathrm{C}-\mathrm{H}$ 键烷基 化，高対映选择性地合成了平面手性二茂铁衍生物(Eq. $6)$.
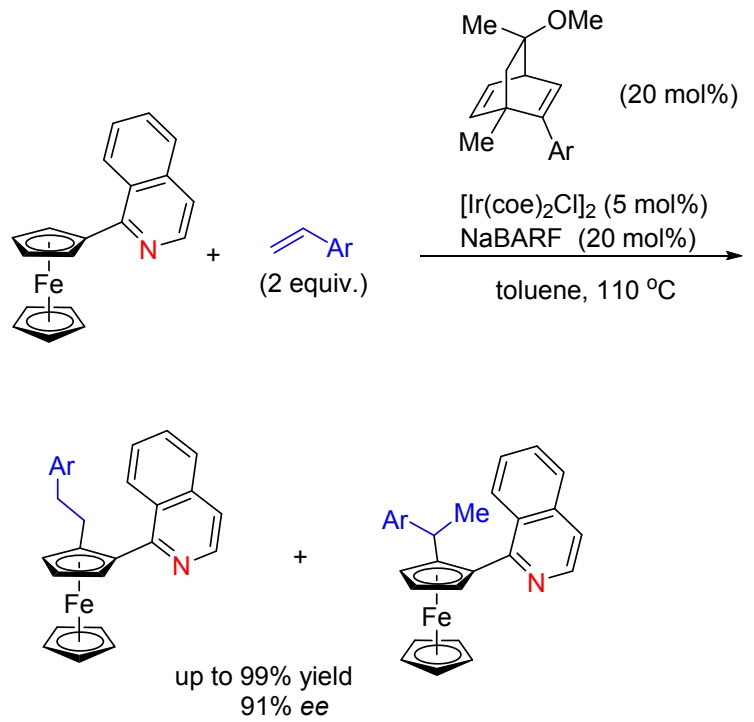

(6)

\section{5 金属钯催化的反应}

2006 年, Kündig 等 ${ }^{[11]}$ 发现以手性联䒺酚骨架的亚 膦酰胺配体 $/ \mathrm{Pd}(\mathrm{dba})_{2}$ 为催化剂, $\mathrm{LiBH}_{4}$ 或 $\mathrm{NaBH}_{3} \mathrm{CN}$ 为氢 源,对称的二卤代芳基金属络合物(铬、钉)芳环上两对映 异位碳卤键能发生对映选择性氢化反应, 从而生成光学 活性的面手性芳基金属络合物(Scheme 1)
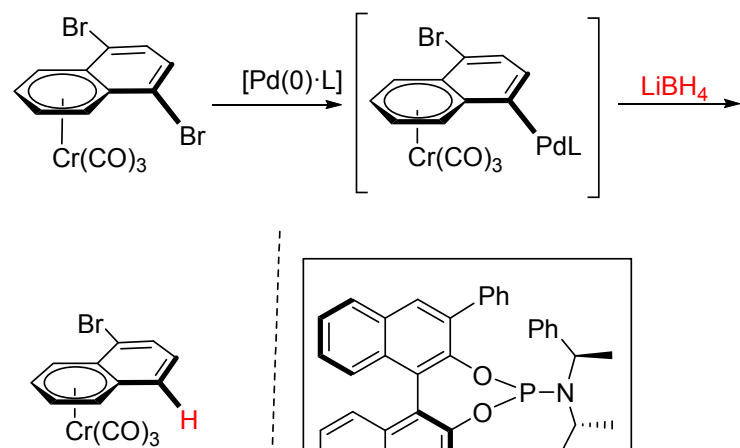

$97 \%$ ee

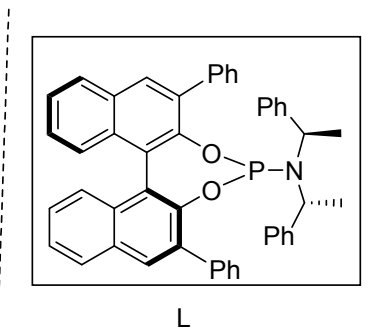

图式 1 钯催化不对称氢化

Scheme 1 Pd-catalyzed asymmetric hydrogenolysis

2011 年该课题组 ${ }^{[12]}$ 利用相同的催化体系实现了对 称的二溴取代的二茂铁衍生物的去对称化还原反应，合 成了具有平面手性的单溴取代的二茂铁衍生物，后者通 过简单的转化即可合成仅具有面手性元素的二茂铁基 膦配体(Scheme 2). 在该反应中, 首先是钯对芳基卤化 物的对映选择性性氧化加成, 之后再用 $\mathrm{Li}\left[\mathrm{BH}_{4}\right]$ 氢化还
原得到平面手性二茂铁衍生物, ee 值可达 $66 \%$; 所得产 物在叔丁基锂的作用下生成芳基锂，进而与二苯基氯化 磷发生亲电取代反应即可得到仅具有面手性二茂铁膦 配体. 利用相同的催化剂 Kündig 还实现了二溴取代慕 的金属络合物的对映选择性 Suzuki-Miyaura 偶联反 应 $^{[13]}$.

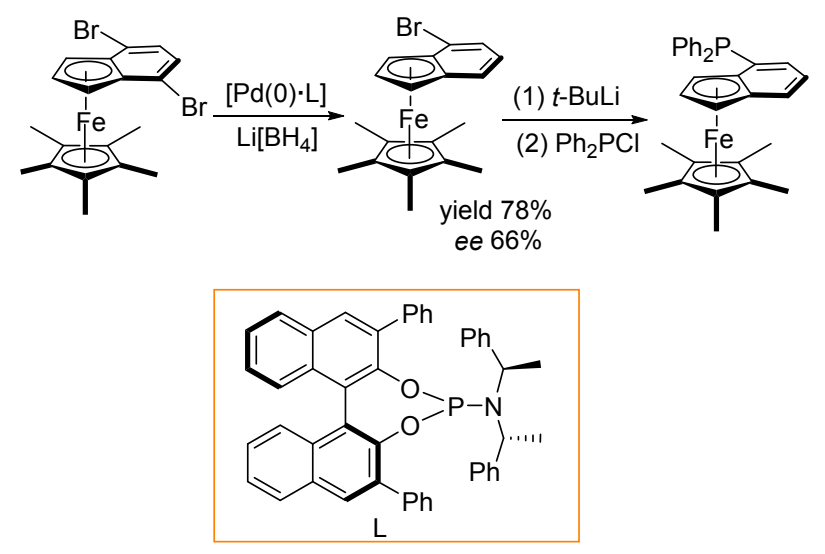

图式 2 钯催化不对称氢化及其应用

Scheme 2 Pd-catalysed asymmetric hydrogenolysis and the application

20 世纪 70 年代, Sokolov 等发现氨基酸配体可以很 好地实现二甲氨基亚甲基二茂铁的直接环钯化，形成平 面手性的环钯化合物. 此后, 关于化学计量 $\mathrm{C}-\mathrm{H}$ 键活 化合成面手性二茂铁化合物的文章相继报道 ${ }^{[14 ~ 16]} .2007$ 年, 游书力等 ${ }^{[17]}$ 报道了 $\mathrm{Pd}(\mathrm{OAc})_{2}$ 催化的二茂基噁唑啉 衍生物茂环上 $\mathrm{C}-\mathrm{H}$ 键和苯环 $\mathrm{C}-\mathrm{H}$ 键的双活化偶联反 应(Eq. 7). 2012 年, 崔秀灵课题组 ${ }^{[18]}$ 报道了 Pd 催化的二 芳基乙炔对 $N, N$-二甲基二茂铁甲胺的脱氢环化反应，合 成了消旋的二茂铁衍生物，产率最高可达 $81 \%$ (Eq. 8). 近年来，催化不对称碳氢活化反应取得了重要的进 展 ${ }^{[19]}$. 余金权课题组 ${ }^{[20]}$ 研究发现手性氨基酸衍生物/二 价钯催化体系是前手性化合物 $\mathrm{C}-\mathrm{H}$ 键不对称活化反应 的高效催化剂. 上述研究结果为二价钯催化的单取代二 茂铁衍生物茂环 $\mathrm{C}-\mathrm{H}$ 键的不对称活化反应研究奠定了 基础.

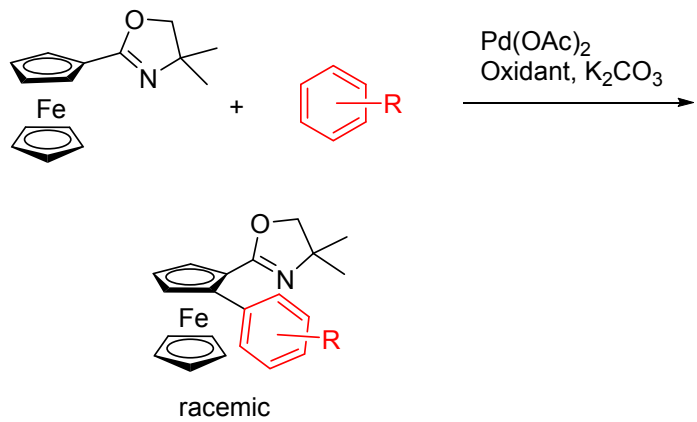





Yield 53\% 81\% racemic

2013 年, 游书力、顾庆等 ${ }^{[21]}$ 将手性氨基酸/二价钯 催化体系成功地应用于不对称 $\mathrm{C}-\mathrm{H}$ 键活化, 高效地合 成了平面手性化合物. 他们以 N-Boc 保护的颕氨基酸和 $\operatorname{Pd}(\mathrm{OAc})_{2}$ 为催化体系, 实现了二甲氨基导向的二茂铁的 芳基化反应, 以高达 81\%产率和 99\% ee 值得到了平面 手性的二茂铁衍生物(Eq. 9). 该工作首次实现了通过钯 催化的 $\mathrm{C}\left(\mathrm{sp}^{2}\right)-\mathrm{H}$ 键活化反应构筑平面手性二茂铁衍生 物, 为平面手性的引入提供了一种新的思路; 研究发现 此类二茂铁化合物可以转化为平面手性的 $\mathrm{P}, \mathrm{N}$ 配体, 并 被初步应用于不对称催化反应的研究.

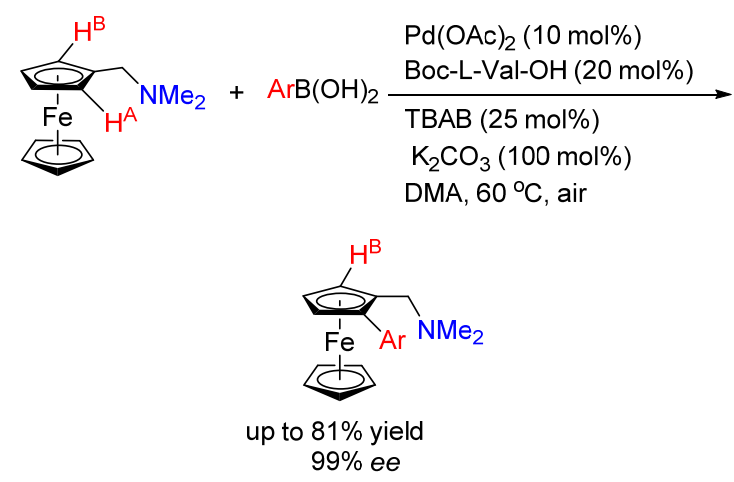

2013 年游书力课题组 ${ }^{[2]}$ 发现: 以相同的催化体系 可实现二芳基乙炔与 $N, N$-二甲基二茂铁甲胺的脱氢环 化反应的高対映选择性转化, 以高达 $99 \%$ 的 $e e$ 值得到 了平面手性二茂铁衍生物(Eq. 10). 该课题组研究发现: 含溴原子取代基的代产物经过简单的转化即可生成平 面手性氮膦配体, 后者已被成功应用于不对称烯丙基烷 基化反应和不对称烯丙基胺化反应(Eq. 11).

2013 年崔秀灵课题组 ${ }^{[23]}$ 报道了另一个构筑平面手 性二茂铁衍生物的方法, 通过不对称脱氢 Heck 反应来 实现(Scheme 3). $\mathrm{Pd}(\mathrm{OAc})_{2}$ 和氨基酸的催化体系可以高 效地催化 $N, N$-二甲氨基亚甲基二茂铁立体选择性地和 多种末端烯烃进行偶联, 从而实现了平面手性二茂铁衍
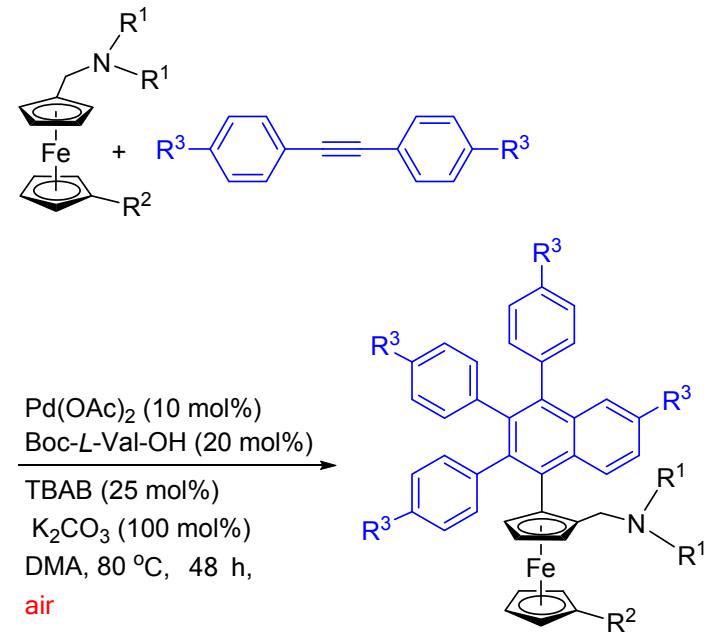

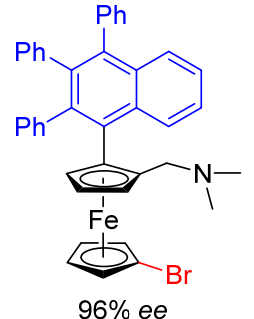

(1) $n$-BuLi

(2) $\mathrm{Ph}_{2} \mathrm{PC}$

THF, $-78^{\circ} \mathrm{C}$

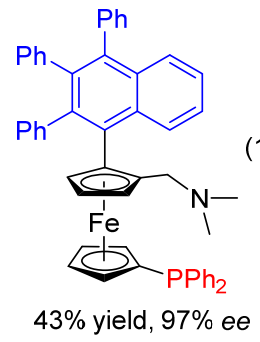

生物的高效构筑. 值得注意的是该催化体系不需要另外 加入氧化剂，体系中 $N, N$-二甲氨基亚甲基二茂铁在空气 中氧的作用下可被氧化, 原位生成带有正电荷的 $N, N$ 二 甲基氨基亚甲基二茂铁离子，并作为终端的氧化剂,实 现 $\operatorname{Pd}(0)$ 和 $\operatorname{Pd}(\mathrm{II})$ 之间的循环, 从而顺利完成催化循环.

2-酰基-1-二甲氨基亚甲基二茂铁衍生物含有酰基 和氨基两个官能团, 通过不同的转换可以转化成为多种 有用的分子，例如 PPFA 和 Josiphos 等优秀配体的类似 物. 2014 年崔秀灵课题组 ${ }^{[24]}$ 以 N-Ac 保护的苯丙氨酸和 $\mathrm{Pd}(\mathrm{OAc})_{2}$ 为催化体系, 通过二价钯催化的启动的不对称 $\mathrm{C}-\mathrm{H}$ 键活化反应实现了 $\mathrm{N}, \mathrm{N}$-二甲氨基亚甲基二茂铁的 酰基化，以高达 85\%产率和 $98 \%$ ee 值合成了一系列平 面手性的 2-酰基-1-二甲氨基亚甲基二茂铁衍生物(Eq. 12). 文献[25]报道的该类化合物的合成包括当量手性胺 辅助下的对映选择性锂化、酰基化、亲电加成和氧化 4 步反应. 该课题组首次通过一锅法不对称直接酰基化来 合成平面手性二茂铁酰基化合物，避免了繁琐的步骤和 苛刻的条件，具有原子经济性和步骤经济性的优点. 以 上用氨基酸衍生物为配体的不对称碳氢活化都是二价 钯启动的反应. 近年来, 零价钯启动的分子内不对称碳 氢活化反应取得了重要的突破, 该策略成功地实现了碳 和硅中心手性的不对称构建 ${ }^{[26]}$. 最近我国化学家利用 零价钯启动的不对称催化反应成功地实现了面手性二 茂铁衍生物的高效、高选择性构建. 

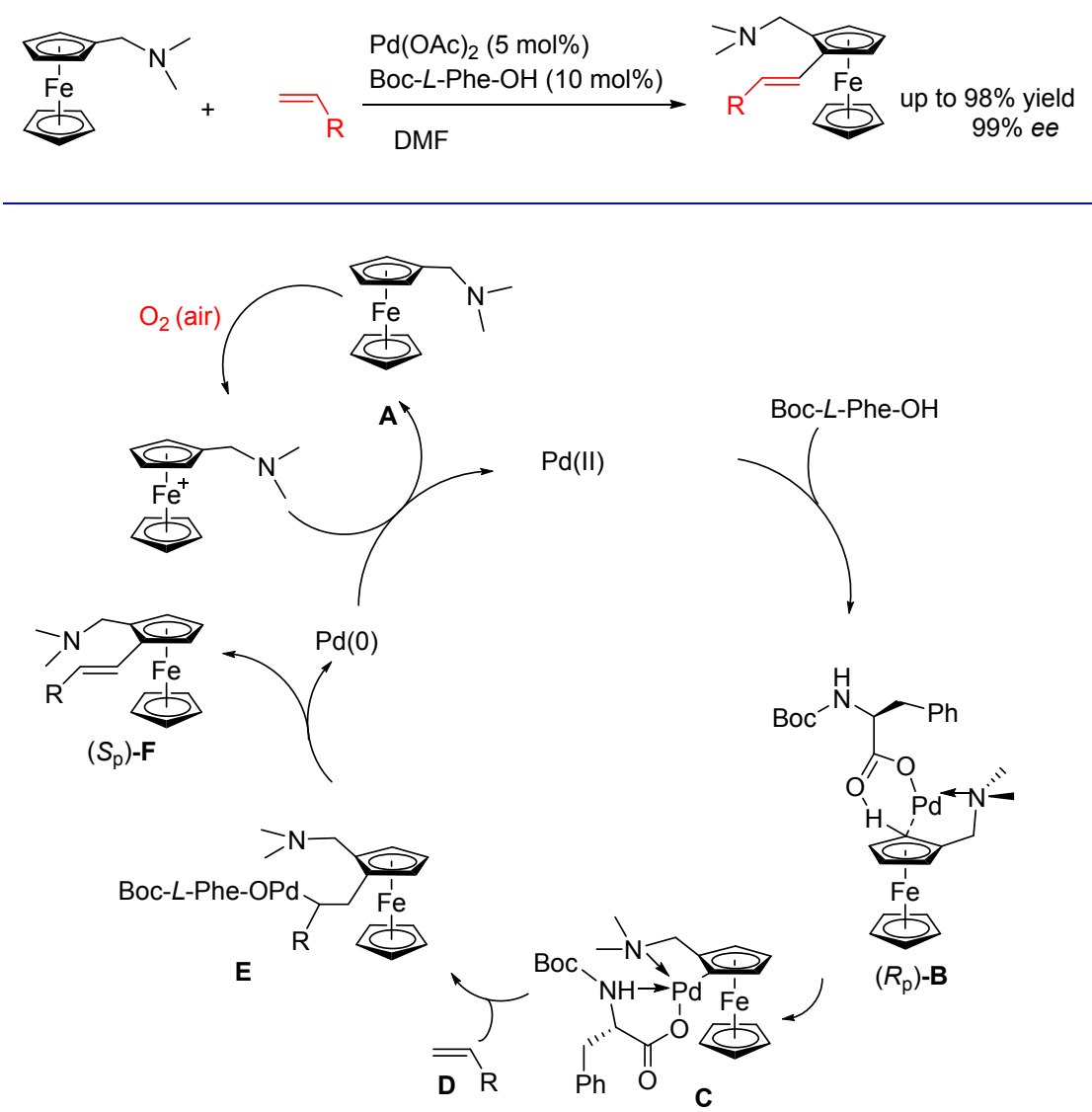

图式 3 不对称脱氢 Heck 反应

Scheme 3 Asymmetric dehydrogenative Heck reaction
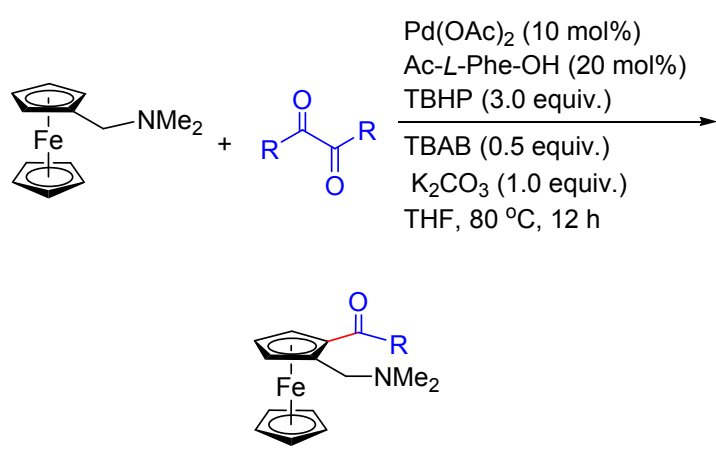

up to $85 \%$ yield $98 \%$ ee

2014 年, 游书力课题组 ${ }^{[27]}$ 报道了零价钯催化的分 子内不对称 $\mathrm{C}-\mathrm{H}$ 键芳基化反应直接构筑平面手性二茂 铁衍生物的研究结果. 他们以 $\left(R_{\mathrm{a}}\right)$-BINAP 为手性配体、 $\operatorname{Pd}(\mathrm{OAc})_{2}$ 为催化剂、碳酸铯为碱、特戊酸为添加剂, 以 高达 $99 \%$ 的收率和 $e e$ 值, 成功合成了平面手性二茂铁 衍生物. 值得指出的是: 所得产物经过一些简单的转化 即可得到二茂铁骨架手性氮膦配体, 该配体可应用于不 对称烯丙基烷基化反应和不对称烯丙基胺化反应 (Scheme 4).

同年，顾振华课题组 ${ }^{[28]}$ 利用手性 BINAP 为配体,
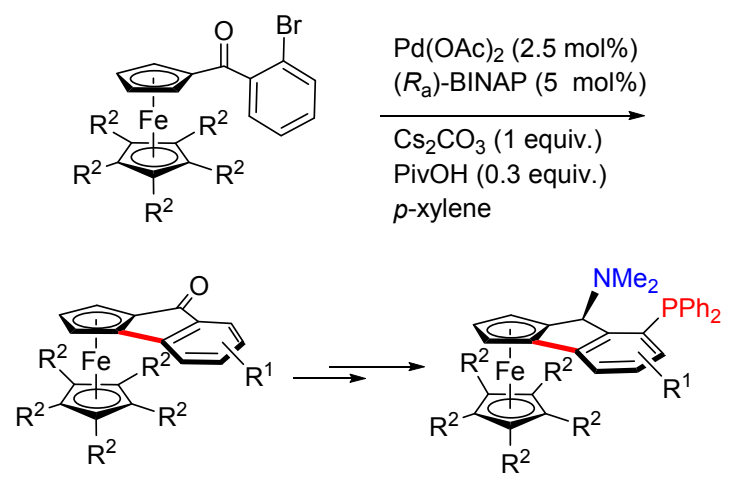

图式 4 钯催化的分子内不对称 $\mathrm{C}-\mathrm{H}$ 键芳基化反应及其应用 Scheme $4 \mathrm{Pd}(0)$-catalyzed asymmetric intramolecular $\mathrm{C}-\mathrm{H}$ bond arylation and the application

$\operatorname{Pd}(\mathrm{OAc})_{2}$ 为催化剂, 碳酸铯为碱的条件下, 也利用钯催 化的不对称 $\mathrm{C}-\mathrm{H}$ 键活化直接合成了平面手性二茂铁衍 生物(Eq. 13). 该反应的底物与游书力课题组报道的底 物几乎相同, 只是断裂的是 $\mathrm{C}-\mathrm{I}$ 键, 值得注意的是该反 应在不加特戊酸的条件下依然可以高收率高选择性地 合成平面手性二茂铁衍生物, 并且对底物的耐受性特别 广泛. 




他们对上述反应可能的反应机理作了简单的介绍 (Scheme 5), 首先是零价钯 Pd 对底物 C-I 键的氧化加成 形成中间体 I; 然后在碳酸铯的作用下脱去一分子的卤 化氢，同时活化茂环其中一个 $\mathrm{C}-\mathrm{H}$ 键，形成中间体 II; 之后再经过还原消除得到最终产物。
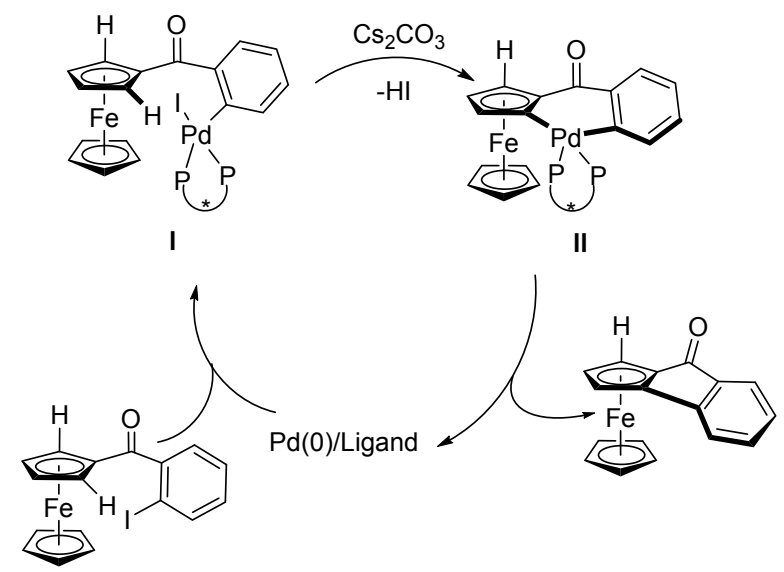

图式 5 推测的反应机理

Scheme 5 Proposed mechanisim

随后, 顾振华课题组 ${ }^{[29]}$ 利用 $\mathrm{Pd}(\mathrm{OAc})_{2} /(R, S a)$ $O$-PINAP 为催化体系, 通过零价 Pd 催化的不对称分子 内 $\mathrm{C}_{\mathrm{p}}-\mathrm{H}$ 芳基化反应实现了平面手性二茂铁并喹啉酩衍 生物的合成(Eq. 14), 取得了优秀的产率和中等的对应 选择性(up to $67 \% e e$ ). 该反应的选择性虽然不高, 但是 反应底物的普适性很强. 他们研究发现添加剂特戊酸虽 可以大幅度提高某些活性底物的反应产率, 但是却使反 应产物的 $e e$ 值大大降低; 对于某些反应底物反应活性 的提高帮助不大, 但是反应产物的 $e e$ 值也大幅降低.

刘澜涛课题组 ${ }^{[30]}$ 报道了通过钯催化 $N$-(2-卤代芳基) 二茂铁甲酰胺类化合物的分子内不对称 $\mathrm{C}\left(\mathrm{sp}^{2}\right)-\mathrm{H}$ 芳基 化构筑平面手性二茂铁并 [1,2-c]-4-喹啉酮类衍生物的 研究. 通过广泛的配体篮选, 他们发现 TADDOL 骨架 的手性亚磷酰胺配体对该反应有其独特的优越性. 在最 佳条件下对底物进行了拓展, 不同取代基的二茂铁甲酰 胺类反应底物都以较高的收率和较好的选择性转化为 平面手性二茂铁并 [1,2-c]-4-喹啉酮类化合物, 最好的结 果取得了高达 $91 \%$ 的产率和高达 $96 \%$ 的 $e e$ 值(Scheme



$$
\begin{aligned}
& \mathrm{Pd}(\mathrm{OAc})_{2}(5 \mathrm{~mol} \%) \\
& \mathrm{L}(10 \mathrm{~mol} \%) \\
& \mathrm{Cs}_{2} \mathrm{CO}_{3}(2.5 \text { equiv. }) \\
& \underset{\text { toluene, } 120^{\circ} \mathrm{C}, 12 \mathrm{~h}}{\longrightarrow}
\end{aligned}
$$

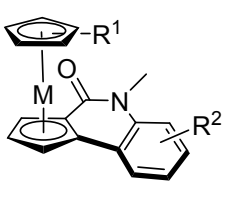

up to $98 \%$ yield $67 \%$ ee

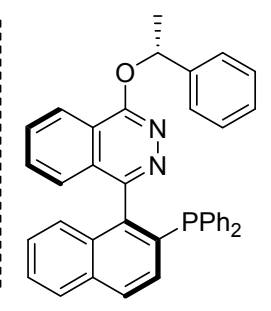

(R,Sa)-O-PINAP, L
6). 当酰胺的 $N$ 上没有保护基团时该反应是不能进行的. 尽管 $N-(2$-氯代芳基)二茂铁酰胺未能发生该反应，但是 $N-(2$-碘代芳基)二茂铁酰胺与 $N-(2$-㴪代芳基 $)$ 二茂铁酰 胺一样可以以较高的收率和较好的选择性转化为平面 手性二茂铁并 $[1,2-c]-4-$ 喹啉酮类化合物. 其可能的反应 机理是: 首先 $\left[\mathrm{Pd}^{0}\right]$ 对 $\mathrm{C}-\mathrm{Br}$ 键的氧化加成形成中间体 $\mathbf{A}$; 然后特戊酸根与 $\mathrm{Br}^{-}$交换, 同时活化茂环其中一个 $\mathrm{C}-\mathrm{H}$ 键, 形成中间体 $\mathbf{B} ; \mathbf{B}$ 脱去特戊酸根形成环钯化合 物 $\mathbf{C}$, 再经过还原消除得到最终产物. 特戊酸对反应的 活性的有很大的促进作用, 对反应产物的 ee 值影响不 大.

\section{6 结论与展望}

平面手性二茂铁类配体在不对称催化中表现出非 常高效的催化活性, 因此发展平面手性二茂铁类衍生物 高效的构筑方法来有着重要的理论价值和实际意义. 目 前, 最常用的还是利用各种手性导向基团诱导的邻位金 属化的方法或者是用化学计量的外加手性辅助剂, 显然 这种策略需要在二茂铁骨架中预先引入中心手性，也需 要使用等物质的量的锂试剂及较为苛刻的反应条件. 在 过去的几十年中, 过渡金属催化的对称分子去对称化的 方法，尤其是过渡金属催化的对映选择性 C-H 键官能团 化的方法取得了很大的成功, 相关结果给面手性二茂铁 衍生物的高效合成提供了新的方法与思路. 最近几年, 过渡金属催化的对映选择性 $\mathrm{C}-\mathrm{H}$ 反应在面手性二茂铁 衍生物的构筑方面得到了初步的应用，也表现出了原子 经济性和步骤经济性等优点. 通过过渡金属催化不对称 $\mathrm{C}-\mathrm{H}$ 键活化构建平面手性二茂铁衍生物及其在不对称 催化领域的应用是一个有重要意义的课题, 仍将是未来 一段时间的研究热点之一. 


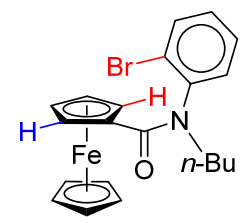

$\mathrm{Pd}_{2}(\mathrm{dba})_{3}(5 \mathrm{~mol} \%)$ Ligand (10 mol\%) $t-\mathrm{BuCO}_{2} \mathrm{H}(30 \mathrm{~mol} \%)$

$\mathrm{Cs}_{2} \mathrm{CO}_{3}$ (1.5 equiv.) toluene, $80^{\circ} \mathrm{C}, 8 \mathrm{~h}$

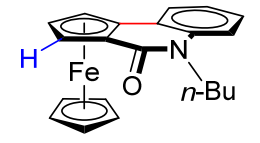

up to $91 \%$ yield up to $98: 2$ er

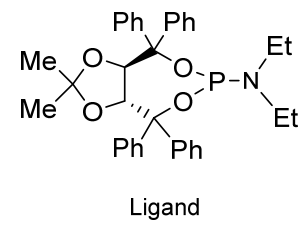

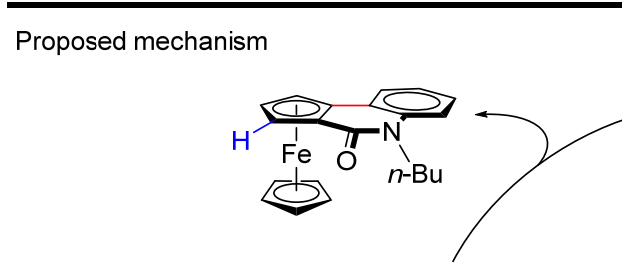
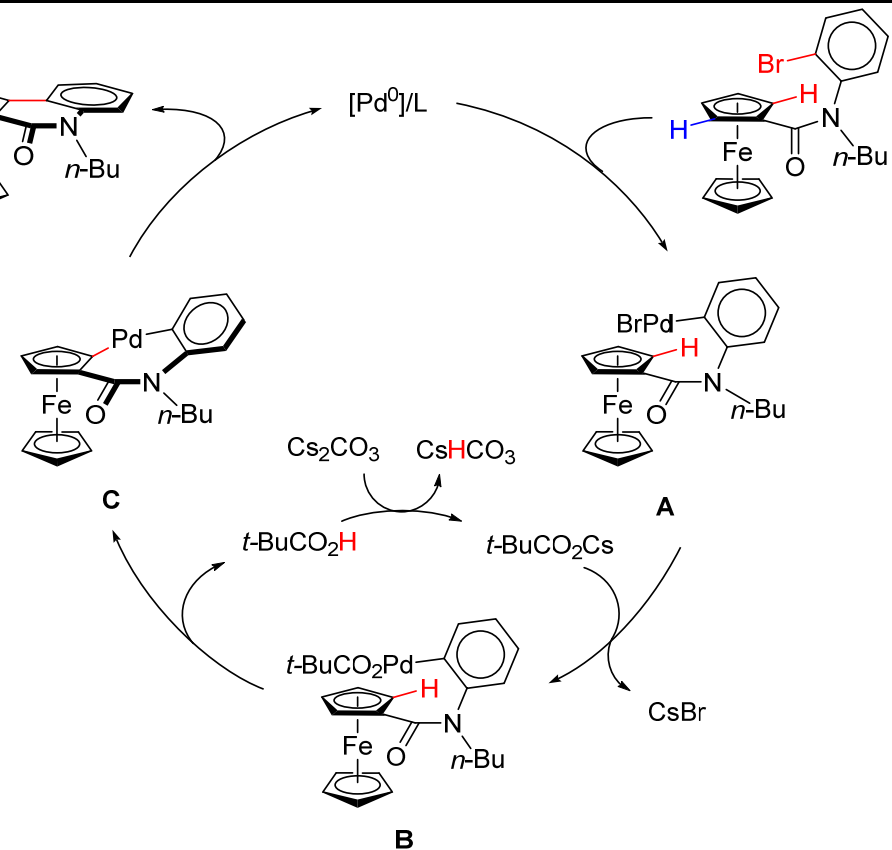

图式 6 分子内不对称 $\mathrm{C}-\mathrm{H}$ 键芳基化反应及其反应机理

Scheme 6 Asymmetric intramolecular $\mathrm{C}-\mathrm{H}$ bond arylation and the proposed mechanisim

\section{References}

[1] Carolina, V. B.; Barry, R. S.; Veronika, K.; Maria, M. S.; Constantinos, G. S. J. Organomet. Chem. 2006, 691, 2785.

[2] (a) Dai, L.-X.; Tu, T.; You, S.-L.; Deng, W.-P.; Hou, X.-L. Acc. Chem. Res. 2003, 36, 659.

(b) Dai, L.-X.; Hou, X.-L. Chiral Ferrocenes in Asymmetric Catalysis, Wiley-VCH, Weinheim, 2010.

(c) Fu, G. C. Acc. Chem. Res. 2004, 37, 542.

(d) Fu, G. C. Acc. Chem. Res. 2006, 39, 853.

[3] Schaarschmidt, D.; Lang, H. Organometallics 2013, 32, 5668.

[4] (a) Zhang, J.-L.; Dong, C.-E.; Han, J.; Yu, Z.-L.; Zhang, L.-F. Chin. J. Org. Chem. 2001, 21, 573 (in Chinese). (张俊龙, 董春娥, 韩杰, 于作龙, 张良辅, 有机化学, 2001, 21, 573.)

(b) Liu, Z.; He, X. Prog. Chem. 2006, 18, 1489 (in Chinese). (刘振德, 何煦昌, 化学进展, 2006, 18, 1489.)

(c) Song, Q.-B.; Dong, Y. Chin. J. Org. Chem. 2007, 27, 66 (in Chinese).

(宋庆宝, 东宇, 有机化学, 2007, 27, 66.)

(d) Li, G.-H.; Liu, X.-J.; Cheng, H.-B. Chem. Res. 2010, 21, 108 (in Chinese).

(黎桂辉, 刘学军, 程红彬, 化学研究, 2010, 21, 108.)

(e) Liu, H.-Q.; Shi, L.; Chen, Q.-A.; Wang, L.; Zhou, Y.-G. Acta Chim. Sinica 2013, 71, 40 (in Chinese).

(刘洪强, 时否, 陈庆安, 王否, 周永贵, 化学学报, 2013, 71, 40.)

(f) Su, M.; Li, Q.; Wang, Y.-G.; Chen, S.-F.; Zhao, H.-Y.; Bian,
Z.-X. Chin. J. Org. Chem. 2013, 33, 815 (in Chinese).

(苏敏, 李晴, 王亚光, 陈树峰, 赵海英, 边占喜, 有机化学, 2013, 33, 815.)

(g) Ye, H.-M.; Wang, W.; Zhu, X.-X.; Chen, W.-Q.; Xie, L.-L.; Yuan, Y.-F. Chin. J. Org. Chem. 2013, 33, 827 (in Chinese).

(叶宏民, 王薇, 朱晓晓, 陈伟强, 谢莉莉, 袁耀锋, 有机化学, 2013, 33, 827.)

[5] Plażuk, D.; Zakrzewski, J.; Salmain, M. Org. Biomol. Chem. 2011, $9,408$.

[6] Siegel, S.; Schmalz, H.-G. Angew. Chem., Int. Ed. 1997, 36, 2456.

[7] Duan, W.-L.; Imazaki, Y.; Shintani, R.; Hayashi, T. Tetrahedron 2007, 63, 8529 .

[8] Ogasawara, M.; Watanabe, S.; Nakajima, K.; Takahashi, T. J. Am. Chem. Soc. 2010, 132, 2136.

[9] (a)Takebayashi, S.; Shibata, T. Organometallics 2012, 31, 4114. For the related aromatic $\mathrm{C}-\mathrm{H}$ activation catalyzed by manganese: (b) Zhou, B. W.; Chen, H.; Wang, C.Y. J. Am. Chem. Soc. 2013, 135, 1264.

(c) Zhou, B. W.; Ma, P. C.; Chen, H.; Wang, C. Y. Chem. Commun. 2014, 50, 14558.

(d) Wang, C. Y. Synlett 2013, 24, 1606.

[10] Shibata, T.; Shizuno, T. Angew. Chem., Int. Ed. 2014, 53, 5410.

[11] (a) Kündig, E. P.; Chaudhuri, P. D.; House, D.; Bernardinelli, G. Angew. Chem., Int. Ed. 2006, 45, 1092.

(b) Mercier, A.; Yeo, W. C.; Chou, J.; Chaudhuri, P. D.; Bernardinelli, G.; Kündig, E. P. Chem. Commun. 2009, 5227.

(c) Mercier, A.; Urbaneja, X.; Yeo, W. C.; Chaudhuri, P. D.; Cumming, G. R.; House, D.; Bernardinelli, G.; Kündig, E. P. Chem. 
Eur. J. 2010, 16, 6285.

(d) W. C.; Urbaneja, X.; Kundig, E. P. Chimia 2010, 64, 177.

[12] Buchgraber, P.; Mercier, A.; Yeo, W. C.; Besnard, C.; Kündig, E. P. Organometallics 2011, 30, 6303.

[13] Urbaneja, X.; Mercier, A.; Besnard, C.; Kündig, E. P. Chem. Commun. 2011, 47, 3739.

[14] Sokolov, V. I.; Troitskaya, L. L.; Reutov, O. A. J. Organomet. Chem. 1979, 182, 537.

[15] Günay, M. E.; Ilyashenko, G.; Richards, C. J. Tetrahedron: Asymmetry 2010, 21, 2782.

[16] Günay, M. E.; Richards, C. J. Organometallics 2009, 28, 5833.

[17] Xia, J.-B.; You, S.-L. Organometallics 2007, 26, 4869.

[18] Zhang, H.; Cui, X.-L.; Yao, X.-N.; Wang, H.; Zhang, J.-Y.; Wu, Y.-J. Org. Lett. 2012, 14, 3012.

[19] (a) Wencel-Delord, J.; Colobert, F. Chem. Eur. J. 2013, 19, 14010.

(b) Zheng, C.; You, S.-L. RSC Adv. 2014, 4, 6173.

[20] (a) Shi, B. F.; Maugel, N.; Zhang, Y. H.; Yu, J.-Q. Angew. Chem., Int. Ed. 2008, 47, 4882 .

(b) Shi, B. F.; Zhang, Y. H.; Lam, J. K.; Wang, D. H.; Yu, J.-Q. J. Am. Chem. Soc. 2010, 132, 460.

(c) Wasa, M. K.; Engle, M.; Lin, D. W.; Yoo, E. J.; Yu, J. Q. J. Am. Chem. Soc. 2011, 133, 19598.

(d) Musaev, D. G.; Kaledin, A.; Shi, B.-F.; Yu, J.-Q. J. Am. Chem. Soc. 2012, 134, 1690.

(e) Cheng, X.-F.; Li, Y.; Su, Y.-M.; Yin, F.; Wang, J.-Y.; Sheng, J.; Vora, H. U.; Wang, X.-S.; Yu, J.-Q. J. Am. Chem. Soc. 2013, 135, 1236.

[21] Gao, D.-W.; Shi, Y.-C.; Gu, Q.; Zhao, Z.-L.; You, S.-L. J. Am. Chem. Soc. 2013, 135, 86.

[22] Shi, Y.-C.; Yang, R.-F.; Gao, D.-W.; You, S.-L. Beilstein J. Org. Chem. 2013, 9, 1891.
[23] Pi, C.; Li, Y.; Cui, X.-L.; Zhang, H.; Han, Y.-B.; Wu, Y.-J. Chem. Sci. 2013, 4, 2675.

[24] Pi, C.; Cui, X.-L.; Liu, X.-L.; Guo, M.-X.; Zhang, H.-Y.; Wu, Y.-J. Org. Lett. 2014, 16, 5164.

[25] (a) Nishibayashi, Y.; Arikawa, Y.; Ohe, K.; Uemura, S. J. Org. Chem. 1996, 61, 1172.

(b) Delacroix, O.; Picart-Goetgheluck, S.; Maciejewski, L.; Brocard, J. Tetrahedron: Asymmetry 1999, 4417.

(c) Delacroix, O.; Andriamihaja, B.; Picart-Goetgheluck, S.; Brocard, J. Tetrahedron 2004, 60, 1549.

(d) Malfait, S.; Pelinski, L.; Brocard, J. Tetrahedron: Asymmetry 1998, 9, 2207.

(e) Picart-Goetgheluck, S.; Delacroix, O.; Maciejewski, L.; Brocard, J. Synthesis 2000, 1421.

[26] (a) Albicker, M. R.; Cramer, N. Angew. Chem., Int. Ed. 2009, 48, 9139.

(b) Anas, S.; Cordi, A.; Kagan, H. B Chem. Commun. 2011, 47, 11483 .

(c) Nakanishi, M.; Katayev, D.; Besnard, C.; Kundig, E. P. Angew. Chem., Int. Ed. 2011, 50, 7438.

(d) Martin, N.; Pierre, C.; Davi, M.; Jazzar, R.; Baudoin, O. Chem. Eur. J. 2012, 18, 4480.

(e) Saget, T.; Lemouzy, S. J.; Cramer, N. Angew. Chem., Int. Ed. 2012, 51, 2238.

[27] Gao, D.-W.; Yin, Q.; Gu, Q.; You, S.-L. J. Am. Chem. Soc. 2014, 136,4841 .

[28] Deng, R.-X.; Huang, Y.-Z.; Ma, X.-N.; Li, G.-C.; Zhu, R.; Wang, B.; Kang, Y.-B.; Gu, Z.-H. J. Am. Chem. Soc. 2014, 136, 4472.

[29] Ma, X.-N.; Gu, Z.-H. RSC Adv. 2014, 4, 36241.

[30] Liu, L.-T.; Zhang, A.-A.; Zhao, R.-J.; Li, F.; Meng, T.-J.; Ishida, N.; Murakami, M.; Zhao, W.-X. Org. Lett. 2014, 16, 5336.

(Qin, X.) 